Revista NEP - Núcleo de Estudos Paranaenses, Curitiba, v.5, n.1, jun. 2019

Dossiê Partidos Políticos e Conexões Familiares

ISSN: 2447-5548

\title{
AS POLÍTICAS PÚBLICAS DE ROBERTO REQUIÃO: UMA AGENDA NEOLIBERAL OU SOCIAL DEMOCRATA?
}

\author{
Daiane Carnelos Resende Laibida ${ }^{1}$
}

\begin{abstract}
RESUMO: Este trabalho tem como objetivo central verificar se as políticas públicas implementadas no governo de Roberto Requião no Paraná (1991-1994, 2003-2006, e 2006-2010) podem ser inseridas, predominantemente, em uma das agendas político-econômica do capitalismo no século XX (social-democrata e neoliberal). Tal indagação se justifica pelo fato de que este político, em seus discursos, se autodeclara avesso ao programa neoliberal, e por isso pretende-se examinar a correspondência, ou não, de seu discurso e de sua prática política.
\end{abstract}

Palavras-Chave: Neoliberalismo; Welfare State; Políticas Requianistas.

\section{LAS POLÍTICAS PÚBLICAS DE ROBERTO REQUIÃO: UNA AGENDA NEOLIBERAL OU SOCIAL DEMÓCRATA?}

RESUMEN: Este estudio tiene como objetivo verificar si las políticas centrales públicas implementadas durante la presidencia de Roberto Requião en Paraná (1991-1994, 2003-2006 y 2006-2010) se puede insertar en su mayor parte en una de las agendas políticas y económicas del capitalismo del siglo XX (socialdemócrata y neoliberal). Esta investigación se justifica por el hecho de que esta política, en sus discursos, afirma ser contrarios al programa neoliberal, y por lo tanto tiene la intención de examinar la correspondencia, o no, de su discurso y su práctica política.

Palabras clave: Neoliberalismo, Estado de Bienestar; Requianistas Políticas.

\section{Introdução}

O objetivo principal deste trabalho é verificar se as políticas públicas implementadas pelo político Roberto Requião, podem ser inseridas em uma das agendas político-econômica do capitalismo no século XX (social-democrata e neoliberal). Tal objetivo se justifica tendo em vista que Requião, em seus discursos, muito criticou as políticas neoliberais, e, por isso, espera-se encontrar mais características da socialdemocracia em suas políticas. Este estudo não pretende abordar todas as políticas públicas elaboradas por este político frente ao governo do Paraná, já que Requião exerceu três mandatos (1991-1994, 2003-2006, e 2006-2010) e isso demandaria um tempo maior, e

\footnotetext{
${ }^{1}$ Doutora em Sociologia pela Universidade Federal do Paraná. Contato: professoradaine@ yahoo.com.br
} 
talvez nem fosse possível. Foram selecionadas, para a presente análise, as políticas com maior destaque na esfera midiática durante o período supracitado.

Para cumprir este objetivo geral, este trabalho está organizado em três seções, as quais cada uma delas corresponde aos objetivos específicos. Na primeira seção será apresentado um breve panorama histórico das etapas do capitalismo, enfatizando a última e atual etapa - o neoliberalismo - em seu contexto maior de surgimento e desenvolvimento, ou seja, na esfera da globalização. A segunda seção adentrará para as questões econômicas e políticas do capitalismo brasileiro, destacando os aspectos do desenho do Estado Moderno (centralização e descentralização), aspectos estes fundamentais para a compreensão da terceira e última seção, que objetiva enquadrar as principais políticas públicas implementadas no governo de Requião em uma das duas agendas do capitalismo (social-democrata ou neoliberal). Por fim, serão apresentadas as considerações finais.

\section{O capitalismo liberal e o dirigido}

O capitalismo enquanto modo de produção originou-se da Revolução Comercial na Europa Medieval, entre os séculos XI e XIV. Porém, a formação social capitalista, ou seja, a formação social em que o modo de produção capitalista domina a infra-estrutura, originou-se com a Primeira Revolução Industrial, embora não seja observado no final do século XVIII, mercados de livre concorrência. A consolidação da indústria fabril na GrãBretanha, posteriormente difundidas à Europa Central e Ocidental e na América do Norte, e a construção de ferrovias e consequente unificação dos mercados nacionais, entre outros fatores, possibilitou a produção e distribuição em massa, a partir da década de 1870, dando origem à Segunda Revolução Industrial. A difusão da indústria veio acompanhada da difusão do governo representativo e do laissez-faire, praticados inicialmente pela GrãBretanha e pelos Estados Unidos, e adotados por todos os povos "civilizados".

O desenvolvimento do capitalismo aguçou as contradições entre as grandes potências, que lutavam incessantemente pelo domínio dos mercados mundiais. Como resultado desta disputa teve-se a Primeira Guerra Mundial, em que duas coligações 
imperialistas se confrontaram, custando milhões de vida e devastando várias regiões da Europa. A Revolução Russa, em 1917, deu início a uma onda revolucionária, que, posteriormente, derrubaria as monarquias da Alemanha, Turquia e Áustria-Hungria. Ao mesmo tempo em que as economias devastadas tentavam se reconstruir importantes avanços democráticos foram observados neste período: a adoção do sufrágio universal em vários países, a extensão de plenos direitos políticos às mulheres, a conquista do poder por partidos do movimento operário (Labour Party na Grã-Bretanha). Porém, este momento positivo foi freado com a crise de 1929 e a depressão que só terminou na década seguinte, com a Segunda Guerra. Esta crise, tida como a pior crise do capitalismo, teve como marca a destruição de valores, taxas de desemprego altíssimas, empobrecimento das massas (Singer, 1998).

Essa situação possibilitou que novas formas de organização política conciliassem desenvolvimento social e desenvolvimento econômico em seus programas. Tais características puderam ser observadas na Suécia, em 1932, quando os social-democratas assumem o poder. Em contrapartida, e com propostas diversas, em 1933, Roosevelt foi empossado nos Estados Unidos e Adolf Ritler na Alemanha. O que estes três governos fizeram em comum foi expandir o gasto público, desvalorizar suas moedas em relação ao ouro e liberar o crédito. Como resultado, suas economias retomaram o crescimento, ainda que lentamente; porém, enquanto na Suécia e nos Estados Unidos houve a expansão dos direitos sociais e políticos, na Alemanha observou-se a revogação dos direitos políticos e anulação das conquistas democráticas.

Singer (1998) atenta para o fato de que, pela primeira vez na história do capitalismo, a economia havia sido resgatada da crise não pela reação espontânea do mercado, mas pela ação do Estado, e, a este momento, Singer chama de "capitalismo dirigido", embora a nomenclatura mais recorrente para este período seja Welfare State ${ }^{2}$. Tal capitalismo, com o término da Segunda Guerra Mundial e a vitória maior dos Estados Unidos, adquiriu um sentido democrático e progressista, consubstanciado no compromisso de todos os governos de manter o pleno emprego.

\footnotetext{
${ }^{2} \mathrm{O}$ welfare state, uma das marcas de prosperidade do pós-guerra, representou em termos gerais um esforço de reconstrução econômica, moral e política. Em relação à economia, rompia com a lógica do mercado, pois previa a segurança do emprego, direitos de cidadania, justiça social, solidariedade e universalismo. Já em relação à política, foi parte de um projeto de construção nacional, dentro da "democracia liberal", contra repressões, como a fascista e a bolchevista. (Esping-Anderson, 1995).
} 
As políticas intervencionistas têm em Keynes o principal precursor, especialmente com a publicação de seu livro 'Teoria geral do emprego, juro e moeda', em 1936. Keynes havia demonstrado que não era a livre concorrência nos mercados de fatores que determinava o nível de emprego e de atividade, mas sim a demanda efetiva, que depende da propensão da população a consumir e das decisões de investir dos empresários. Deste modo, o desemprego, observado pós-crise de 29 , não seria resolvido pela aceitação de salários menores por parte dos trabalhados, ou seja, este desemprego poderia ser involuntário, uma vez que salários menores, caso fosse geral, aumentaria a deflação, visto que os demais preços tenderiam a cair também, deprimindo a demanda, já que os compradores postergariam seus gastos na expectativa de queda maior ainda dos preços. A redução do desemprego e a elevação do nível de atividade viriam, segundo Keynes, com a elevação da demanda efetiva, e isto, naquelas circunstâncias, poderia ser feito apenas pelo governo, seja por meio de política fiscal (aumento dos gastos públicos), seja por política monetária (expansão da oferta de moeda e redução das taxas de juros) ${ }^{3}$. (Keynes, 1982).

Os social-democratas, adeptos da proposta keynesiana, no entanto, preferiram ativar a demanda por meio dos gastos sociais. De acordo com Przeworski (1991), a estrutura dos sistemas capitalistas instituídos pelos social-democratas esteve pautada nos seguintes preceitos:

a) O Estado responsabiliza-se pelas atividades que não são lucrativas para as empresas privadas, mas que se fazem necessárias para a economia como um todo;

b) O governo regula, especialmente por meio de políticas anticíclicas, o funcionamento do setor privado;

c) O Estado, aplicando medidas pautadas pela teoria do bem-estar, atenua os efeitos distributivos do funcionamento do mercado.

Entre os anos de 1945 e 1973, o sistema capitalista prosperou, de forma que o aumento da produtividade não elevou o desemprego, e a preocupação com o desemprego tecnológico foi sanada com a expansão de novos setores, especialmente o de serviços. Cabe aqui salienta a importância do sistema de gerenciamento econômico internacional, nomeado de Bretton Woods, que estabeleceu, em 1944, algumas das principais regras para

\footnotetext{
${ }^{3} \mathrm{Na}$ conclusão de Keynes (1982), o governo poderia coordenar a conjuntura via políticas anticíclicas, manipulando a produção estatal a fim de contrabalançar as oscilações da produção capitalista.
} 
Revista NEP - Núcleo de Estudos Paranaenses, Curitiba, v.5, n.1, jun. 2019

ISSN: 2447-5548

as relações comerciais e financeiras entre os países mais industrializados do mundo. Esse sistema se configurou no primeiro que objetiva governar as relações entre Estados-Nações independentes. Foi uma espécie de organizador econômico pós-segunda guerra mundial, assim como o Consenso de Washington ${ }^{4}$.

Este período de crescimento econômico foi também um período de grandes revoluções, como por exemplo, comunistas, ditaduras militares, revoluções coloniais e culturais. Em relação à expansão do programa socialista-comunista, a ameaça mais constante ao capitalismo, Przeworski (1991) afirma que a mediação pacífica entre este e o socialismo seria a social-democracia, a qual oferecia crédito aos pequenos burgueses, pensões aos empregados do colarinho branco, salário mínimo aos operários, proteção aos consumidores, instruções aos jovens, salário-família às famílias, enfim, não se ocupava em lutar pelos objetivos específicos de uma classe (como o operariado), mas sim pela coletividade, ou seja, os pobres, os consumidores, os usuários de transporte público etc.

Enquanto que no liberalismo iniciado em meados do século XIX, o papel do Estado era proteger o mercado, impedir que o monopólio destruísse a concorrência, e fazer com que as classes sociais aceitassem o "veredito do mercado", no "capitalismo dirigido" ou no modelo social-democrata, a função do Estado era dirigir o mercado, induzindo os agentes econômicos a adotar condutas favoráveis ao pleno aproveitamento dos recursos. (Singer, 1998)

A partir de 1965, o modelo social-democrata começa a entrar em crise. A mais apontada foi a crise financeira, ou seja, a incapacidade do Estado de cobrir os déficits oriundos dos gastos. Com isso, para manter-se, o Estado teria que cobrar mais tributos, o que para muitos geraria inflação e acabaria provocando desemprego e mais necessidade de gastos. Para Harvey ${ }^{5}$, citado por Souza (1997), o modelo era rígido e não podia responder às novas demandas que começavam a aparecer por volta da década de 70. Entre os pontos de rigidez, o autor destaca:

\footnotetext{
${ }^{4}$ Por ter sido realizado em Washington, em meados da década de oitenta, foi subscrito pelos Estados centrais do sistema mundial, abrangendo o futuro da economia mundial, as políticas de desenvolvimento e especificamente o papel do Estado na economia, todas as dimensões da globalização são afetadas por este consenso (Santos, 2001).

${ }^{5}$ HARVEY, D. Condição Pós-moderna. Uma pesquisa sobre as Origens da Mudança Cultural. São Paulo Loyola, 1993.
} 
a) rigidez dos investimentos de capital fixo de larga escala e de longo prazo em sistemas de produção de massa, que impediam maior flexibilidade de planejamento e presumiam um crescimento estável, de mercados de consumo, invariante;

b) rigidez dos mercados, na alocação e nos contratos de trabalho (especialmente no chamado setor monopolista);

c) rigidez crescente dos compromissos do Estado na medida em que programas de assistência (seguridade social, direitos de pensão, etc.) aumentavam sob pressão para manter a legitimidade em um momento em que a rigidez na produção restringia expansões da base fiscal para gastos públicos;

d) rigidez do poder profundamente entrincheirado da classe trabalhadora - o que explica as ondas de greve e os problemas trabalhistas do período de 1968-72.

Com a crise do welfare state, houve um refluxo da onda liberal anterior à crise de 1929, o chamado neoliberalismo. Governos conservadores voltaram ao poder de posse das reformas neoliberais, que pregavam a redução dos gastos do Estado ou o aumento dos tributos, a não intervenção no mercado, a flexibilização dos direitos trabalhistas, a privatização dos serviços públicos, entre outros aspectos. Cabe ainda mencionar a crise do petróleo do final da década de 1970, que pode ser considerada um divisor de águas, pois abalou profundamente muitos países do globo, por o petróleo não ser uma fonte renovável, serviu de argumento para ao aumento do preço deste combustível, caso que ocasionou alguns conflitos e uma corrida incessante em busca desse tesouro.

O quadro abaixo apresenta um panorama geral das características do modelo neoliberal em contraposição ao modelo social-democrata.

QUADRO - AGENDA NEOLIBERAL E SOCIAL-DEMOCRATA

\begin{tabular}{|c|c|}
\hline Agenda Neoliberal & Agenda Social-Democrata \\
\hline Desregulamentação & Desconcentração Político-Administrativa \\
\hline Privatização & Municipalização \\
\hline Descentralização/Desconcentração & Sociedade Solidária e Organizada \\
\hline
\end{tabular}


Revista NEP - Núcleo de Estudos Paranaenses, Curitiba, v.5, n.1, jun. 2019

\begin{tabular}{|c|c|}
\hline Redução do Estado/Estado Mínimo & Autogestão, Co-gestão, Participação \\
\hline Fragmentação do Social & Novas Formas de Organização do Político \\
\hline Indivíduo/Mercado & Coletivo/Estado \\
\hline
\end{tabular}

FONTE: SOUZA (1997).

O neoliberalismo possui este caráter de "neo" por ser uma proposta de reformulação do liberalismo do século XIX, porém, num contexto de intensa globalização ${ }^{6}$. O fenômeno da globalização problematizou a existência do Estado-Nação e colocou em dúvida a existência do modelo do Welfare State e consequentemente, o arranjo que este articulava do social ao cultural. Emergiu com isso, uma nova configuração envolvendo uma forte tendência de deslocamento do centro de gravidade para o âmbito global, fato que ao mesmo tempo tem favorecido a reemergência do âmbito local. Conforme Santos (2005), ao contrário da globalização implicar em um processo de homogeneização, tem resultado na combinação entre certo efeito universalizador e a reemergência de particularismos, dando evidência à diversidade local.

De acordo com Ianni (1998, p.27), “o que predomina, na época em que se dá a globalização, é a visão neoliberal do mundo”. A globalização não é um fato acabado e sim um processo em marcha que enfrenta obstáculos, sofre interrupções, mas também generaliza-se e aprofunda-se como tendência, e, por isso, há nações e continentes nos quais esse processo pode-se desenvolver ainda mais, como é o caso da África e da América Latina. Segundo o autor, a história do capitalismo pode ser lida como a história da mundialização, da globalização do mundo, e consiste num vasto processo histórico simultaneamente social, econômico, político e cultural (Ianni, 2002).

\footnotetext{
${ }^{6}$ Vários os autores utilizam-se de outra terminologia em detrimento à globalização. Chesnais, por exemplo, prefere o termo mundialização, pois, globalização estaria imbuído de conotações ideológicas e ambíguas, já mundialização é o mais indicado para expressar "uma nova configuração do capitalismo mundial e nos mecanismos que comandam seu desempenho e sua regulação". (CHESNAIS, 1996, p.13). Esse autor faz uso do conceito de "mundialização do capital" para fazer a articulação das dimensões políticas e econômicas, pois dessa forma é mais fácil entender o sistema capitalista no seu novo estágio: "a palavra mundial permite introduzir, com mais força do que o termo global, a ideia der que, se a economia se mundializou, seria importante construir depressa instituições políticas mundiais capazes de dominar o seu movimento" (idem, 1996, p.24).
} 
Para Milton Santos (2006), é mais sensato falar em globalizações e considerar o tema diferenciando-o em três sentidos: como fábula (referindo-se ao discurso hegemônico, à "máquina ideológica" que a sustenta como visão de mundo); como realidade (quanto ao caráter perverso de suas consequências sociais); e como possibilidade outra (sobre o quão possível é pautar-se uma outra globalização).

Santos (2001, p.26) menciona que a globalização se constitui em um processo multifacetado, compreendendo não apenas a dimensão econômica, conforme a maioria da literatura tem enfatizado, mas dimensões culturais, sociais, jurídicas e religiosas, que se inter-relacionam em um processo complexo. No âmbito da dimensão econômica, o autor profere que a globalização econômica é sustentada pelo consenso neoliberal (Consenso de Washington), cuja três principais inovações institucionais são: restrições drásticas à regulação estatal da economia; novos direitos de propriedade internacional para investidores estrangeiros; inventores e criadores de inovações susceptíveis de serem objeto de propriedade intelectual (Robinson, 1995); subordinação dos Estados nacionais às agências multilaterais tais como Banco Mundial, o FMI e a Organização Mundial do Comércio. Em relação ao caráter geral do referido consenso, as receitas por ele impostas ora foram tratadas por modo da jaula de ferro ora do modo da jaula de borracha, mais flexível. De acordo com o autor, os países que mais sofrem com as imposições do consenso neoliberal, são os periféricos e os semiperiféricos, uma vez que o receituário neoliberal é transformado pelas agências financeiras multilaterais em condições para negociação da dívida externa através de programas de ajustamento estrutural.

Na esfera da globalização social, o consenso neoliberal é o de que o crescimento e estabilidade econômicos assentam na redução de custos salariais, para o que é necessário liberalizar o mercado de trabalho, reduzindo os direitos liberais, proibindo a indexação de salários aos ganhos de produtividade e os ajustamentos ao custo de vida e eliminando a prazo a legislação sobre o salário mínimo, objetivando o impedimento do "impacto inflacionário dos aumentos salariais"; a contração do poder de compra interno que resulta desta política deve ser suprida pela busca de mercados externos. Isto posto, o conceito de consumidor substitui o de cidadão e o critério de inclusão deixa de ser o direito para ser a solvência - os pobres são os consumidores que ultrapassam os limites do sobre 
endividamento e medidas compensatórias são criadas para disfarçar a situação. (Santos, 2001)

Para Desai (2005), a globalização é vista como uma reação interna ao declínio da lucratividade do capital sob o regime keynesiano, e nessa nova configuração, o Estado deixa a posição de controle da economia e passa a ser um ator. O esgotamento das políticas keynesianas, segundo Dupas (2005), ocorrido a partir da década de 80, associada à crise energética, conduziram o grande capital na busca de novas fronteiras de acumulação, quer por meio das conquistas de novos mercados, quer mediante a redução de custos de produção.

Segundo Balanco (1999), o processo de globalização consiste na fase mais avançada do capitalismo. Com o declínio do socialismo, o sistema capitalista se disseminou de forma avassaladora pelo mundo. A consolidação do capitalismo iniciou a era da globalização, principalmente, econômica e comercial. O processo de globalização estreitou as relações comerciais entre os países e as empresas - através das inovações tecnológicas, como redes de comunicação e modernização dos meios de transporte; a partir destas transformações tornou-se possível uma maior e melhor difusão de informação entre as empresas e instituições financeiras e principalmente o rápido transporte de mercadorias entre os países, fato que facilitou a ligação entre os mercados mundiais e deu origem, assim, a divisão internacional do trabalho, que se tornou clássica entre as multinacionais. $\mathrm{O}$ autor ainda destaca que a globalização está associada à regularidade do capitalismo, e fundamenta o impulso às transformações permanentes do mesmo.

Depois de retomar os pressupostos gerais das duas "fases" do capitalismo, o dirigido e o liberal de Singer, ou o social-democrata e (neo) liberal, este último indissociável do processo de globalização, fenômeno que perpassa todas as esferas do mundo social, cabe agora adentrar para a compreensão do Brasil no contexto da globalização, com destaque para os fenômenos econômicos e políticos.

\section{Política e economia no Brasil no contexto da globalização}


Revista NEP - Núcleo de Estudos Paranaenses, Curitiba, v.5, n.1, jun. 2019

ISSN: 2447-5548

Almeida (2007) apresenta um passeio pela história do Estado no Brasil Contemporâneo, com a finalidade de analisar as mudanças da organização estatal no Brasil, em termos de maior ou menor concentração de recursos de poder no governo central, apontando o foco para as transformações pelas quais passou a Federação, ou seja, os movimentos de centralização e descentralização. Ao longo de sua história, o Brasil teve sete Constituições, foi por duas vezes Estado unitário e depois federação, passou de monarquia parlamentarista (1824-1889) a república presidencialista (1891-1961), depois a república semipresidencialista (1961-1963) e de volta a república presidencialista (1930), teve quatro sistemas eleitorais e seis sistemas de partidos distintos. Entretanto, apesar de todas as mudanças institucionais, as eleições se firmaram como principal mecanismo de acomodação, competição e contestação pacífica durante 180 anos de vida política.

As estruturas estatais podem se organizar em torno de um centro nacional de decisões ou da existência de autoridades subnacionais. O Brasil é um caso bem sucedido de estabelecimento de alguns aspectos básicos do Estado Nacional: manteve a integridade do imenso território que estivera sob domínio português (período colonial) e institucionalizou as regras do jogo político que geraram um sistema representativo. Entre 1822-1850 controlou movimentos que poderia ter levado à secessão e à fragmentação territorial. As fronteiras externas foram se desenhando, via guerras e acordos diplomáticos, ao longo do século XIX até a primeira metade do século XX. Ainda que a penetração completa das instituições públicas tenha demorado muito tempo (formas de poder privado continuaram importantes século XX adentro), o Estado brasileiro conseguiu definir precocemente seus limites e fazê-los reconhecer no plano internacional. A homogeneidade das elites políticas no Brasil, ainda no período monárquico, foi o fator principal para o mantenimento da unidade territorial do país (idem, 2007).

A constituição republicana de 1891 deu ao Estado brasileiro uma estrutura federativa. Diferente dos EUA, que o modo federativo veio para juntar unidades políticas previamente independentes, no Brasil veio para manter juntos membros de uma coletividade que aspiram a separar-se e organizar-se como Estados independentes. De 1891 a 1930, Primeira República ou República do café com leite, observou-se, então, um Estado descentralizado, um federalismo dual, no qual havia divisão de competências entre os entes federados. 
No Estado Novo presidido por Getúlio Vargas, desapareceram a federação e as instituições democráticas e representativas. O congresso foi fechado, os governos dos Estados reduzidos à condição de províncias sem autonomia e entregues à interventores do governo federal, os partidos políticos proibidos e as eleições suspensas por prazo indeterminado. Pela primeira vez, a disputa e negociação política deixaram de recorrer ao mecanismo eleitoral e passaram a depender exclusivamente da arbitragem do governo federal e da mediação das burocracias centrais. Elites políticas dissidentes, intelectuais antiliberais e reformadores e elites civis e militares vinculadas à organização do Estado central foram os grandes propulsores e beneficiários da centralização e da expansão do aparato e das atribuições do Estado.

Segundo Almeida (2007), entre os anos de 1930 a 45, o país teve a definição de políticas de promoção do desenvolvimento econômico, de construção de instituições, mecanismos e instrumentos de regulação e intervenção estatal nos mercados, e também de criação e extensão dos direitos sociais, segundo os princípios do corporativismo. Neste período criaram-se empresas públicas para a produção de insumos básicos, requerida pela expansão industrial. Organismos especializados se encarregaram de regular alguns mercados de produtos primários: café, açúcar e álcool, madeira etc. Um conjunto de políticas ativas de promoção industrial foi posto em marcha: incentivos fiscais, crédito subsidiado, proteção tarifaria, reserva de mercado, proteção cambial. Foi também na era Vargas que ocorreu a extensão limitada de direitos sociais e construção das fundações de um sistema de proteção social; regulamentação das relações trabalhistas, os sindicatos e a negociação coletiva reconhecida (sob controle governamental e no interior de um sistema de tipo corporativista). Empregados urbanos da indústria e serviços viram assegurados direitos sociais básicos: jornada de trabalho, salário mínimo, férias, contrato de trabalho, previdência social os trabalhadores agrícolas, que eram maioria, ficaram excluídos desta incipiente cidadania social.

No período de 1945 a 1964 foram realizados os primeiros experimentos democráticos de fato, com eleições e competição partidária, e a este momento, Almeida (2007) chama de federalismo complexo, já que se observou uma distribuição complexa de competências entre os três níveis de organização. Câmara e Senado na defesa dos interesses regionais e descentralizadores se contrapunham à perspectiva do executivo 
federal, com forças modernizadoras e centralizadoras. Logo, estes anos foram de alternância entre centralização e descentralização.

Cabe destacar neste período a criação da CEPAL (Comissão Econômica para a América Latina e o Caribe) em 1948, pelo Conselho Econômico e Social das Nações Unidas. O seu principal objetivo é o monitoramento das políticas direcionadas à promoção de desenvolvimento econômico da região latino-americana e assessorar as ações encaminhadas para sua promoção e contribuir para reforçar as relações econômicas dos países da área, tanto entre si como as demais nações do mundo. Um dos principais pensadores da CEPAL foi Celso Furtado, cujas obras estão relacionadas principalmente à construção da nação diante das diversas formas de dominação internacional e do pacto interno de dominação, em prol da luta pela emancipação nacional. Um dos grandes fatores que torna o Brasil dependente do capital estrangeiro, segundo o autor, é que o Brasil produz matéria prima e não tem a tecnologia suficiente para transformá-la, nessa conjuntura os países com maior tecnologia tem o domínio sobre os que não tem essa técnica muito desenvolvida, ocasionando a dependência. Assim, sugere Furtado que num país sem técnica própria, sem formação de capitais que pudessem ser desviados para outras atividades, a única saída no século XIX era desenvolver o comércio internacional. Para desenvolver o comércio interno seria preciso que o organismo econômico alcance certo grau de complexidade, caracterizado pela autonomia tecnológica, pois "para contar com a cooperação do capital estrangeiro, a economia deveria primeiro retomar o crescimento com seus próprios meios" (Furtado, 1974, p.111)

Sob comando dos militares (1964-1984), houve intensa centralização do poder. Foi também neste período que o Brasil viveu um novo ciclo desenvolvimentista: expansão das empresas públicas produtoras de bens e serviços, assim como as políticas de promoção industrial; o aparato de regulação econômica tornou-se mais amplo e complexo; e um sistema de proteção social do tipo conservador se expandiu, diversificou e atingiu maturidade. Pendências como a Reforma Agrária e a inexistência de um padrão de financiamento que comportasse o então "dinamismo" industrial haveriam de ser solucionadas. Enquanto os Estados mais dinâmicos e prósperos queriam mais autonomia, os Estados atrasados exigiam um governo federal forte para que seus interesses pudessem 
prevalecer nas propostas de planejamento e desenvolvimento ${ }^{7}$. Para Draibe e Henrique (1988), a crise dos anos 60 apresentou a possibilidade da existência das primeiras formas do welfare state brasileiro.

A constituição de 1988 fixou competência comum aos três níveis de governo no que diz respeito ao desenho de políticas e à provisão de serviços de educação, saúde, habitação etc. Na prática, o governo federal desempenhou um papel decisivo na definição dos termos da cooperação entre as três esferas de governo, reservando para si as funções de formulação de políticas e de regulação dos diferentes sistemas de políticas sociais. Do ponto de vista programático, a constituição de 1988 era descentralizadora em temas fiscais e sociais. No plano fiscal, a descentralização de recursos para Estados e municípios se fez acompanhar de um aumento expressivo da carga tributária e dos recursos a disposição do governo federal. Por outro lado, a constituição democrática ampliou a proporção dos recursos fiscais compartilhados destinados a Estados e municípios. O fundo de participação de Estados e municípios (FPEM), principal instrumento de redistribuição de recursos tributários entre entes federativos, foi redesenhado em benefício dos governos subnacionais (Almeida, 2007).

É interessante mencionar que a descentralização observada com a constituição de 88 no Brasil, como também a descentralização na América Latina, foi inspirada no modelo neoliberal, estando este representado pelos seus agentes: o Fundo Monetário Internacional, o Banco Mundial e o Banco Interamericano de Desenvolvimento. As elites políticas locais, teórica e ideologicamente enfraquecidas por terem renunciado a um projeto nacional, convertem-se em intermediários e praticantes locais das políticas centrais. Trata-se, então, de uma mudança de qualidade das políticas estatais e de transferência de recursos públicos para o setor privado nacional e transnacional. $O$ modelo democratizante de descentralização pode ser visto em três eixos: político, econômico e administrativo. A sua proposta está articulada com a definição do papel e da função do Estado. O principal desafio desse projeto consiste em oferecer aos movimentos sociais, urbanos e municipais condições para que se transformem em atores diante do Estado, que se descoloniza dos

\footnotetext{
${ }^{7}$ Dentre os defensores de um governo federal forte, encontra-se o Paraná. Neste Estado, até meados dos anos 60, não foi possível observar uma reversão do caráter centralizador do crescimento econômico. Em 70, o Estado apresentou uma grande modernização na agricultura e um intenso processo de industrialização e urbanização. Estas transformações tiveram fim ainda no início da década de 80 , com o alto índice de desemprego e a recessão econômica (CASTRO, 2005).
} 
interesses oligárquicos ao mesmo tempo em que se descentraliza e amplia a cidadania (Felicíssimo 1994).

Por fim, observou-se nesta seção um esboço de um resgate histórico do Brasil do século XX, com ênfase nas transformações advindas do processo da globalização. Mas o principal objetivo era demonstrar que este país, por mais que tenha tido um desenvolvimento econômico tardio em relação aos países europeus e aos Estados Unidos, respondeu, de alguma maneira, às transformações globais, e a Constituição de 88 é um bom exemplo dessa "adaptação". Na esfera de organização do Estado, a opção descentralizadora é por vezes normativa ${ }^{8}$, pois, na prática, os entes federados ainda são muito dependentes do executivo federal. Neste sentido, a opção por determinadas políticas públicas de um governo estadual depende muito de uma estrutura maior, seja ela fiscal/orçamentária, conforme observado anteriormente, seja ela pela própria lógica político-partidária do jogo político. Em todo caso, o que se pretende na última seção deste trabalho é verificar se as políticas públicas implementadas por Roberto Requião no Paraná apresentam um perfil mais atrelado à agenda social-democrata, considerando as devidas ressalvas quanto às possibilidades de atuação de um governo estadual neste arranjo federativo.

\section{As principais políticas públicas Requianistas}

O Paraná, assim como todas as unidades federativas do Brasil, possui dificuldades estruturais para uma organização política administrativa efetiva, seja ela do modelo neoliberal, como é a tendência mundial, ou de caráter social-democrata. Como não é o objetivo dessa pesquisa abordar as dificuldades estruturais do Estado para a "aderência" a um modelo político, pois seria objeto para outro estudo, nesta seção pretende-se verificar

\footnotetext{
${ }^{8}$ É interessante mencionar que a discussão sobreo processo de descentralização dos Estados e Municípios do Brasil é muito mais ampla e complexa do que a apresentada nesta seção. Uma das referências neste debate é Marta Arretche. Para ela, "as reformas do Estado de tipo descentralizador supõe uma expansão seletiva das funções do governo central, mais especificamente o fortalecimento de suas capacidades administrativas e institucionais na condução e regulação de políticas setoriais implementadas pelos governos subnacionais e do próprio processo de descentralização" (1996, p.64).
} 
se os programas implementados por Roberto Requião que segundo discursos do mesmo, possuem algumas características da plataforma social-democrata ${ }^{9}$, já que o político em questão é um dos maiores críticos do modelo neoliberal, conforme pode ser observado abaixo:

\begin{abstract}
Não nos deixemos seduzir pela onda neoliberal que, hoje sabemos, simplesmente significou o desmonte da máquina pública em favor dos interesses de setores privilegiados da sociedade. $\mathrm{O}$ discurso neoliberal, aparentemente modernizante, na verdade, não passa do mais arcaico patrimonialismo, confundindo a coisa pública com as posses privadas dos detentores do poder. Aqui no Paraná, ao contrário, optamos por desfazer o mito do 'fazedor de obras' em prol de um conceito ético de administração, com criteriosa aplicação dos recursos públicos e estrito controle de gastos. A ousadia, ao invés de aplicá-la nos lances de rapina que caracterizam a onda 'neoliberal', preferimos praticá-la na seleção de programas de governo de perfil simples, mas eficazes, em áreas fundamentais para o desenvolvimento econômico e social, induzindo mecanismos para a melhor distribuição de renda e geração de empregos. Ao lado disso, investimentos públicos pesados na educação, segurança e saúde, garantindo à população os equipamentos básicos para uma vida melhor. (ARTIGO DE REQUIÃO: O PARANÁ E A MODERNIDADE).
\end{abstract}

Observa-se, nesta citação, não apenas a crítica de Requião ao modelo neoliberal, mas sua preferência por políticas que priorizam as áreas de maior interesse aos cidadãos menos desprovidos de recursos. É mister ressaltar que Requião entra para a política paranaense num período profícuo para este discurso, o período de transição democrática.

Os cidadãos desse período acreditam que essa nova conjuntura lhes garante direitos sociais, além dos direitos políticos. As reivindicações relativas ao atendimento da “cidadania social", conceito elaborado por T.H. Marshall (1967) - "um tipo de igualdade humana básica, associada com uma concepção de membro pleno de uma comunidade", solicitam que a segurança e as oportunidades sejam compartilhadas por todos. As políticas sociais respondem a essas reivindicações por meio da oferta de serviços básicos de saúde, educação e, principalmente, através da distribuição de alimentos e da manutenção da renda. Este tipo de modelo democrático não se constitui unicamente na garantia dos direitos políticos; seu advento melhorou visivelmente a proteção aos direitos sociais. As reformas econômicas e os gastos sociais não eram vistos como um problema soma-zero,

\footnotetext{
${ }^{9}$ Cabe salientar que, de acordo com o objetivo deste estudo, e não reduzindo este modelo, analisaremos o indivíduo Requião enquanto reprodutor de resquícios da social-democracia em seus programas políticos.
} 
sendo que os gastos públicos com políticas sociais cresceram financiados pelo menos em parte por receitas tributárias maiores.

Esses programas de melhorias devem ser processados através das instituições representativas. O processo democrático pode aprimorar a qualidade técnica das políticas de reforma e propiciar bases para o apoio continuado desta. Destarte, a democracia é um valor autônomo pelo qual muitas pessoas lutaram, inclusive, contra regimes autoritários. Para se consolidar a democracia, através da hegemonia das forças - que necessitam aprender a canalizar suas demandas e organizar seus conflitos nos marcos das instituições democráticas - as instituições devem exercer um papel eficaz na formulação e na prática de políticas que influenciem as condições de vida: "Desse modo, nossa abordagem socialdemocrata às reformas orientadas ao mercado requer um direcionamento das reformas para o crescimento, a proteção do bem-estar material contra os custos de transição das reformas e uso pleno das instituições democráticas na formulação e implementação das políticas de reforma”. (Przeworski, 1991, p.211)

Roberto Requião ao longo de sua carreira política optou por direcionar a maior parte de suas políticas às questões sociais, uma herança ideológica advinda de seus antepassados, podemos citar algumas de seus principais programas balizados num modelo próximo da social-democracia. Como exemplo da 'municipalização', pode-se mencionar o sistema de saúde, que passou a ser responsabilidade dos municípios, estando o Estado incumbido do gerenciamento e apoio técnico a estes. Dentre as 'novas formas de organização' de Requião estão à centralização dos gastos públicos, com a finalidade de prevenir desperdícios e evitar irregularidades, a determinação de concursos públicos para contratação de pessoal no Paraná, e a inovação do programa 'Panela Cheia'. A implantação de Sub-Secretarias por Requião pode ser entendida como uma medida de 'desconcentração político-administrativa'; e o aspecto de 'autogestão, co-gestão, participação' pode ser ilustrado através da criação da Ouvidoria Geral, como também das Sub-Prefeituras. Na 'sociedade solidária e organizada' estão alguns programas como 'POVO', 'Casa da Família', 'Primeiro Emprego', entre outros.

Os projetos implantados por Requião em seus pleitos possuem algumas características social-democratas, contemplando as seguintes diretrizes políticas e programas: 
a) Redução em até $40 \%$ do preço da energia elétrica, por mecanismos diretos e indiretos, para atrair empresas do Brasil e do mundo para regiões deprimidas do Paraná;

b) Garantia de preço mínimo para as culturas estratégicas que diversifiquem a agricultura;

c) Isenção de impostos para micro e pequenas empresas, em troca de empregos ofertados por estas;

d) Programa 'Primeiro Emprego', que busca incentivar toda a empresa que der o primeiro emprego a jovens por um período de seis meses a um ano, ficando as obrigações trabalhistas por conta do Estado.

Draibe e Henrique (1988) proferem que o Welfare State no Brasil foi construído, sendo caracterizado pela centralização política e financeira no governo federal e nas ações sociais, fragmentação institucional, exclusão da população à participação política, o autofinanciamento social, a privatização e o clientelismo que ainda persiste em muitos segmentos sociais. Os autores apontam caminhos para as políticas sociais no Brasil:

$1^{\circ}$ Descentralização político-institucional: é o espaço de discussão de políticas públicas com a população. Porém, há dois problemas com isso: primeiro, esses espaços nem sempre são democratizados, vindo a prevalecer um comportamento político arbitrário; ou seja, uma ligeira tendência em reduzir despesas, e isso pode ser um discurso político;

$2^{\circ} \mathrm{O}$ social: a elevação do grau de participação popular em diferentes níveis de todos os processos de implantação das políticas sociais;

$3^{\circ}$ Setor privado/ lucro e setor privado/sem lucro: é uma tendência de mudança nos modos de gerir bens e serviços sociais. Alteraram-se as relações entre Estado e mercado público e o privado, assim como, os sistemas de produção e consumo dos equipamentos sociais, podendo ocorrer uma desresponsabilização do Estado.

$4^{\circ}$ Distribuição de produtos/bens "in natura" à população pobre é o fortalecimento do assistencialismo;

$5^{\circ}$ Renda mínima: o valor proposto não garante plena cidadania aos indivíduos.

Diferentemente de Jaime Lerner, um dos maiores representantes do neoliberalismo ${ }^{10}$ no Paraná, cujo governo foi marcado pela privatização de estatais,

\footnotetext{
${ }^{10} \mathrm{O}$ neoliberalismo defende a privatização do bem-estar, um retorno aos benefícios seletivos, ao invés de universais, e a aceitação de uma maior diferenciação nos ganhos. Já os seus críticos defendem uma estratégia de investimento social, com programas ativos para o mercado de trabalho, treinamentos e educação
} 
Requião defende as estatais e as utiliza para consecução de alguns de seus programas.

Apesar da onda neoliberal que atingiu o Brasil, principalmente a partir dos anos 90, Requião adotou uma postura de oposição ideológica e prática, contrariando interesses das mais diversas esferas políticas:

\begin{abstract}
Vivemos uma séria crise social. O modelo de desenvolvimento que foi implantando-se em nosso País, ao longo do tempo, privilegiou os mais ricos, aumentando sua riqueza, e ampliou a já larga faixa de pobres e miseráveis. Analfabetismo, desemprego, doenças endêmicas, mortalidade infantil, aumento crescente dos índices de delinquência infanto-juvenil e de criminalidade, tudo isto é subproduto de um crescimento econômico desordenado, despreocupado da dimensão social do desenvolvimento. Reverter tal situação é uma questão eminentemente política. Dificilmente a mera assistência social será capaz de dar conta da multiplicidade de problemas que são gerados, cada dia, pelo modelo econômico brasileiro. Entretanto, não existe dúvida de que precisamos atender as situações emergenciais. São homens e mulheres, velhos e crianças concretas, de carne e osso, que hoje estão ao desabrigo, passam fome, sofrem com as doenças. As necessidades do cotidiano desse imenso cortejo de irmãos nossos mantidos na faixa da pobreza e da miséria não podem esperar que políticas sociais $\mathrm{e}$ econômicas mais abrangentes venham a resolver o problema de forma mais consistente. Essas pessoas precisam ser atendidas aqui e agora. Para isto, os trabalhos de assistência social precisam ser rápidos, eficazes e lúcidos. A experiência tem demonstrado que a centralização das ações nas mãos do Estado, nessa área, dispersa esforços, dilapida recursos. Daí porque optamos pelo trabalho em parceria com os municípios. (ARTIGO DE REQUIÃO: O MUNICÍPIO E A QUESTÃO SOCIAL).
\end{abstract}

O perfil econômico utilizado por Requião na implementação de seus programas e projetos parece ser de inspiração social-democrata, com o intuito de preservar o patrimônio do Estado e de elaborar políticas públicas sociais. Dentre os programas com características do wefare state pode-se citar o "Leite das Crianças". Este se propõe a distribuir um litro de leite às crianças cujas famílias estão abaixo da linha da pobreza. O programa é a junção do governo com a sociedade civil organizada - incentiva o agricultor paranaense, apoiando o produto local, gerando emprego e renda e fortalecendo a agroindústria do Estado.

O leite distribuído recebe um tratamento especial, sendo enriquecido com ferro e vitaminas A e D. O programa visa diminuir a desnutrição das crianças paranaenses e atende, prioritariamente, crianças de 6 a 36 meses. Outro grupo focalizado pelo programa é o de mães nutrizes que estejam participando das campanhas de aleitamento materno e as gestantes com acompanhamento pré-natal. A justificativa do programa está elencada no

permanentes, diminuindo as diferenciações do neoliberalismo, construindo assim uma visão socialdemocrata. 
fato das famílias de baixa renda apresentarem grande incidência de desnutrição infantil, o que compromete o desenvolvimento ósseo, motor e mental das crianças ainda nas fases iniciais de vida e interfere na capacidade de alfabetização e educação. O 'Leite da Crianças' objetiva reduzir as deficiências nutricionais, contribuindo, com isso, para a redução dos índices de morbidade e mortalidade infantil. Dentre as propostas para a efetivação do programa, está a distribuição de leite pasteurizado, o estímulo ao aleitamento materno e a difusão de informação e procedimentos relativos à educação sanitária, nutrição e higiene pessoal.

Seguindo a linha de políticas sociais implementadas por Roberto Requião podemos citar o programa "Luz Fraterna", como já foi trabalhado visa a diminuição e até mesmo a gratuidade da luz, para a população de baixa renda. A "Tarifa Social da Água” também segue a mesma linha, ou seja, programas que cerceiam o "assistencialismo".

A questão dos transgênicos, também pode ser vista como uma forma de "proteção" dos pequenos agricultores locais. Roberto Requião proibiu o embarque de soja transgênica pelo Porto de Paranaguá sob a alegação de que as empresas de biotecnologia ainda não tinham respostas concretas para os possíveis impactos das mudanças genéticas nas pessoas e no meio ambiente, afirmando constantemente em seus discursos que "manter a soberania sobre a multiplicidade das sementes desenvolvidas pelos produtores brasileiros é fundamental para a independência do Estado e do país", e segue:

A soja transgênica representa a dominação dos nossos agricultores. Nossa reação contra ela no Paraná não é apenas contra o monopólio da Monsanto, mas também para que possamos, progressivamente, evidenciar aos consumidores a qualidade do que é produzido e exportado pelos produtores paranaenses. (...) Se a produtividade da soja transgênica fosse realmente fantástica, poderíamos até pensar em plantá-la, mas a produtividade paranaense é uma vez e meia maior que a americana. (AGÊNCIA ESTADUAL DE NOTÍCIAS, 2005).

O governador proibiu o plantio $^{11}$, a comercialização e a exportação de soja transgênica, e passou a pleitear junto ao Ministério da Agricultura que o Paraná seja considerado 'Área Livre de Transgênico'. Através de um decreto regulamentado a Lei

\footnotetext{
${ }^{11}$ Apenas 574 produtores do Paraná possuem licença para plantar a soja transgênica , mediante assinatura de um Termo de Compromisso, Responsabilidade e Ajustamento junto ao Ministério da Agricultura.
} 
14.861/05, Requião determina a rotulagem dos produtos comercializados no Estado que contenham ingredientes transgênicos.

Já a intensa luta de Requião contra as concessionárias de pedágios reforça a defesa do "patrimônio público" em detrimento da terceirização. Nas estradas, Requião viveu uma verdadeira guerra judicial. Existiam 38 ações em andamento contra as empresas concessionárias, que, segundo ele, conseguiram do ex-governador Jaime Lerner contratos desfavoráveis ao Estado. O governador defendeu o fim dos pedágios, os quais considera "uma aberração", e é contra a transferência das rodovias à iniciativa privada, alegando que o Paraná arrecada o suficiente para as obras rodoviárias.

Por fim, os programas de Requião, reforçados por seus discursos, possuem um intenso teor valorativo. As atividades norteadas pela ética são diretamente relacionadas a duas formas, segundo Weber (1999): a ética da convicção e a ética da responsabilidade. A primeira pressupõe uma crença em algo "visto" como imutável e atemporal, e a segunda se refere à lógica da realidade, da ação movida pelos fatos. Cabe salientar que as duas se relacionam de alguma maneira, apesar de serem independentes. Através dessa classificação weberiana, podemos visualizar algumas ações de Requião na política seguindo o modelo da ética da convicção, como no caso da formação de seu grupo político, pouco variável em suas gestões, e também pelo formato aderido por ele em suas políticas públicas, que, muitas vezes, se repetem em seus pleitos. As políticas implementadas por Requião podem ser pensadas a partir dois modelos "éticos" de Weber, como no caso dos transgênicos, dos bingos e dos conflitos com as concessionárias do pedágio no Paraná, nos quais segue os pressupostos da responsabilidade do político junto às suas convicções.

\section{Considerações Finais}

Neste trabalho foram observados os processos de transformação do sistema capitalista, enfatizando as duas etapas ao longo do século XX, referentes à atuação econômica e política do Estado. As transformações perpassaram estas duas esferas, constituindo-se num processo global de organização das estruturais e das relações sociais. Neste interim, observou-se como o Brasil reagiu a este processo, com destaque aos 
Revista NEP - Núcleo de Estudos Paranaenses, Curitiba, v.5, n.1, jun. 2019

movimentos pendulares de centralização e descentralização advindos das letras constitucionais, tendo como principal reflexo do neoliberalismo e da globalização, a Constituição de 1988.

Tomadas às devidas ressalvas quanto ao poder de atuação dos governos estaduais, não tão autônomos do executivo federal, verificou-se que a maioria das políticas públicas implementadas pelo político Roberto Requião no Paraná, está moldada mais no modelo do capitalismo dirigido (Welfare State) do que no modelo Neoliberal, embora seja também possível subjugá-las de assistencialistas, quando pensadas num contexto geral. De todo modo, tal fato pode estar alicerçado ao marketing político de Requião, e uma forma de diferenciação que pode culminar em votos e vitória eleitoral.

Este trabalho é apenas um ensaio de uma proposta de tese mais ampla, que objetiva fazer uma análise aprofundada do Estado do Paraná, para então adentrar às políticas públicas de Requião (que se autodeclara anti-neoliberalismo, e tal afirmação compreende os pressupostos desta agenda mencionados no quadro 1) e compará-las às políticas de Jaime Lerner (o genuíno governador neoliberal do Paraná), a fim de verificar em qual governo houve maior crescimento e desenvolvimento econômico do Estado.

\section{Referências}

ALMEIDA, Maria Hermínia Tavares de. O Estado no Brasil Contemporâneo: Um passeio pela história. In ALCANTARA E MELO (org.), A democracia Brasileira. Balanços e perspectivas para o século 21, Ed. Humanitas, 2007.

ARRETCHE, Marta T. S. "Mitos da Descentralização: Mais Democracia e Eficiência nas Políticas Públicas", in: Revista Brasileira de Ciências Sociais, 31 (11), julho, 1996: 4466.

BALANCO, Paulo. As transformações do capitalismo: formulações teóricas para a composição de uma dialética da globalização. In: IV Encontro Nacional de Economia Política, Porto Alegre-RS, junho de 1999.

CARDOSO, Fernando Henrique. O Modelo Político Brasileiro e Outros Ensaios. São Paulo: Difusão Européia do Livro, 1972. 
CASTRO, Demian. Mudança, Permanência e Crise no Setor Público Paranaense: um balanço da trajetória estadual na segunda metade do século XX. Tese (Doutorado em Economia). Unicamp: Campinas, 2005.

CHESNAIS, F. A mundialização do capital. São Paulo: Xamã, 1996.

DESAI, M. A vingança de Marx: A ressurgência do capitalismo e a morte do socialismo estatal. São Paulo: Códex, 2003.

DRAIBE, S.; HENRIQUE, W. "Welfare State", Crise e gestão da crise: um balanço da literatura internacional. Revista Brasileira de Ciências Sociais, 6 vol. 3, fev. 1988.

DUPAS, G. (coordenador). América Latina no início do século XXI: perspectivas econômicas, sociais e políticas. São Paulo: Unesp, 2005.

ESPING-ANDERSEN, G. O futuro do Welfare State na nova ordem mundial. São Paulo: Lua Nova, 1995.

FURTADO, C. Formação econômica do Brasil. $12^{a}$ edição rev. São Paulo:

Nacional,1974.

IANNI, Otávio. A sociedade global. 10ª ed., Rio de Janeiro: Civilização Brasileira, 2002.

IANNI, Otávio. Globalização e neoliberalismo. São Paulo em Perspectiva, 12 (2), 1998. Disponível em: 〈http://www.seade.sp.gov.br/produtos/spp/v12n02/v12n02_03.pdf〉. Acesso em: 03 maio 2018.

KEYNES, J. M. Teoria geral do emprego, do juro e da moeda. Rio de Janeiro: Atlas, 1982.

MARSHALL, T. H. Cidadania, classe social e status. Rio de Janeiro: Zahar, 1967.

OLIVEIRA, R. V., MOREIRA, E. M., Sentidos da globalização: um desafio ao pensamento sociológico. Revista Raízes vol. 27, nº 1. Campina Grande 2008.

PRZEWORSKI, A. Capitalismo e social-democracia. São Paulo: Companhia das Letras, 1991.

ROBINSON, W. “Globalization Nine Theses ou our Epoch”, Race and Class. 1995 (13$31)$.

SANTOS, Boaventura de Sousa. Os Processos da globalização, in Santos, Boaventura de Sousa (org.), Globalização: fatalidade ou utopia?. Porto: Edições Afrontamento, 2001.

SANTOS, M. Por uma outra globalização: do pensamento único à consciência universal. Rio de Janeiro: Record, 2006. 
Revista NEP - Núcleo de Estudos Paranaenses, Curitiba, v.5, n.1, jun. 2019

SINGER, P. Para além do neoliberalismo: a saga do capitalismo contemporâneo. São Paulo em Perspectiva, 12 (2), 1998. Disponível em:

$<$ http://www.seade.sp.gov.br/produtos/spp/v12n02/v12n02_01.pdf. Acesso em 01/06/2018>. Acesso em: 3 maio 2018.

SOUZA, M.T.A. Argumentos em Torno de um "Velho" Tema: A descentralização. Dados, 1997, vol.40, nº 3 .

WEBER, M. Economia e Sociedade. Brasília: Ed. UNB, 1999 (vol.2).

Outras fontes:

O MUNICÍPIO E A QUESTÃO SOCIAL (ARTIGOS DE REQUIÃO) O PARANÁ E A MODERNIDADE (ARTIGOS DE REQUIÃO) OS PARCEIROS NA CONSTRUÇÃO DO FUTURO (ARTIGOS DE REQUIÃO) SITES CONSULTADOS

Casa Civil: http://www.casacivil.pr.gov.br/

Agência Estadual de Notícias: http://www.aenoticias.pr.gov.br

Recebido em: 26 maio 2019.

Aceito em: 10 jun. 2019. 